\title{
Food for Mood-Does the Way We Feel Really Reflect the Way We Eat?
}

\author{
Ursula Werneke \\ Associate Professor in Psychiatry Umeå University and Consultant Psychiatrist \\ Sunderby Research Unit, Umeå University, Umeå, Sweden \\ Email: uwerneke@gmail.com
}

Received November $10^{\text {th }}$, 2013; revised December 25 ${ }^{\text {th }}$, 2013; accepted January $5^{\text {th }}$, 2014

\begin{abstract}
Copyright (C 2014 Ursula Werneke. This is an open access article distributed under the Creative Commons Attribution License, which permits unrestricted use, distribution, and reproduction in any medium, provided the original work is properly cited. In accordance of the Creative Commons Attribution License all Copyrights (C) 2014 are reserved for SCIRP and the owner of the intellectual property Ursula Werneke. All Copyright @ 2014 are guarded by law and by SCIRP as a guardian.
\end{abstract}

\section{Introduction}

Trying to influence the way we feel through the way we eat continues to enjoy immense popularity. Its intuitive appeal is greatly amplified by modern electronic media. For instance, keying "food for mood" recently into my search engine yielded a staggering $153,000,000$ hits on $4^{\text {th }}$ June 2013 . Within ten days, this number had gone up by an impressive eight million to $161,000,000$ hits. But what is the food-mood connection; does the way we eat influence the way we feel or does the way we feel impact on the way we eat or does it work both ways? And how can we therapeutically capitalize on such a connection, irrespective of which way it may work?

\section{Out of Balance-Out of Mind?}

The concept "food for mood" originates from the idea that an illness occurs when the body is out of balance. Thus, it seems only natural that restoring the balance through eating well could restore health. The idea is over 2000 years old. It has been part of the different ancient medicine systems such as traditional Chinese medicine and the Aryurveda, the traditional Indian medical practice. For the Western world, Hippocrates developed similar views (Hillier, 1991). But at the turn of the $19^{\text {th }}$ century, it became increasingly possible to pin down many illnesses to specific causes. For the first time, it became possible to develop effective and specific cures for many acute illnesses of the time, such as the treatment of infections with antibiotics. This was followed by the development of modern antidepressants and antipsychotics. Undoubtedly, this led to great advances in the treatment of mental disorders such as depression; most physicians and patients alike would not want to do without. But it also led to a tendency to see health problems just in biologicalmedical terms and ignore social and environmental factors (Hillier, 1991). And despite this medical view of mental ill health, it has proven difficult to find specific biological causes and cures for many mental health problems including depression.

For the sufferer of low mood, this increasingly uni-dimensional approach may lead to a sense of loss of control. Some of the control may be "clawed back" by modifying our lifestyle including the way we eat. But there are also downsides to this concept. Firstly, there may be a sense of guilt in those who think that some poor life style choice has brought on a mental health problem in the first place. Then, there is a risk that patients and physicians alike may drown in the sheer dearth of recommendations of how to live and eat well. More likely than not, most physicians will neither have the time nor the expertise to discuss life-style decisions in detail in busy out-patient clinics. Finally, many people, particularly when depressed, may not be able to process and appraise information given on diets and lifestyle.

\section{A Banana a Day...}

The idea of tracing illness back to a lack of a specific food component lies somewhat between the concept of illness as a system out of balance and illness as a result of a single medical cause. Indeed, for some health problems, when there is a clearly identified deficiency, this model works very well. For instance, we know that a lack of vitamin $\mathrm{C}$ lies behind scurvy. We also know that lack of iodine may lead to an underactive thyroid gland. But for other health problems it seems to work less well.

We know that depression is associated with a lack of serotonin, yet eating foods containing high amounts of the precursor L-tryptophan, such as bananas or turkey, do not cure depression (Young, 2007). Chocolate, containing polyphenols that may act on gamma-amino-butyric acid and adenosine, has been classically credited with mood-lifting properties. But clinical evidence for individuals suffering from major depression remains limited, even an increased sense of calmness and contentedness has recently been demonstrated for people without mental health problems (Pase et al., 2013). Also, chocolate products tend to contain considerable amounts of sugar and fat. This is required to make cocoa palatable, but adds more calories to our diet. So what about oily omega-3 fatty acids found in oily fish, foods rich in vitamin D or folic aid? Again, the evidence remains limited (Sanhueza et al., 2013), most likely because food-based intervention trials are extremely difficult to conduct.

\section{Supplements for Anyone?}

Even trials using standardized supplements instead of nonstandardized foods often yield only preliminary or inconclusive results. For instance, a recent meta-analysis concluded that the 
treatment effect of omega-3 fatty acids was non-significant (Hannestad \& Bloch, 2012), only to be countered by a re-analysis finding the opposite (Martin et al., 2012). Some supplements, such as folic acid, may work best if used complementarily, i.e. in addition to, rather than alternatively, i.e. instead of conventional treatments (Taylor et al., 2004). Vitamin D supplements may only be worth considering in people who clearly have a vitamin $\mathrm{D}$ deficit or who live in geographical regions where sun exposure is low during winter time (Parker \& Brotchie, 2011). They may work less well in those without an obvious vitamin D deficiency. This suggests that nutritional deficits identified in mental disorders do not automatically pave the way to treatment strategies. It is much easier to show that the lack of substance may lead to a deterioration of mood than the replacement of the substance lead to an improvement. Because once a depressive episode is set into motion, it may maintain itself, even if a precipitating factor such as a nutritional deficit is corrected.

\section{The Tip of the Iceberg}

Possibly, the failure to deliver robust evidence for food or supplement based interventions also stems from the fact that major depression is a multi-factorial condition. Genetic, social and psychological factors may play an equally important role as food deficiencies and all these factors may conspire together to bring on a major depressive episode. But if many factors cause or contribute to a mental health problem, it is unlikely that fixing just one factor will solve the whole problem. However, if a factor such as a clearly identified nutritional deficiency, could be rectified it should. Thus, correcting underlying nutritional deficits may be necessary to treat depression, but in most cases this is not sufficient and nor will it ever be.

\section{Lifestyle Instead of Diet}

As multifactorial problems require multifactorial solutions, it follows that lifestyle interventions covering various aspects of wellbeing may be superior to dietary interventions for most sufferers of major depression. We know for instance that physical activity is beneficial for mood (as long as we do not overdo it). Alcohol, smoking and substance abuse are other worthwhile aspects to consider (Berks et al., 2013). And finally, supportive psychotherapy and motivational interviewing are integral constituents of many life-style interventions. Sometimes, it is even possible to get the best of both worlds through one single intervention. After all, the best way to stock up on vitamin D is to go out and take a walk in the sun.

\section{Conflict of Interest}

Ursula Werneke is writing a book in a related area to be published by Kiener Verlag, Munich, Germany

\section{REFERENCES}

Berk, M., Sarris, J., Coulson, C. E., \& Jacka, F. N. (2013). Lifestyle management of unipolar depression. Acta Psychiatrica Scandinavica Supplement, 443, 38-54. http://dx.doi.org/10.1111/acps.12124

Bloch, M. H., \& Hannestad, J. (2012). Omega-3 fatty acids for the treatment of depression: Systematic review and meta-analysis. Molecular Psychiatry, 17, 1272-1282. http://dx.doi.org/10.1038/mp.2011.100

Hillier, S. (1991). The limits of medical knowledge. In G. Scambler (Ed.), Sociology as applied to medicine (pp. 175-184). London: Ballière Tindall.

Martins, J. G., Bentsen, H., \& Puri, B. K. (2012). Eicosapentaenoic acid appears to be the key omega- 3 fatty acid component associated with efficacy in major depressive disorder: A critique of Bloch and Hannestad and updated meta-analysis. Molecular Psychiatry, 17, 11441149. http://dx.doi.org/10.1038/mp.2012.25

Parker, G., \& Brotchie, H. (2011). "D” for depression: Any role for vitamin D? Food for thought II. Acta Psychiatrica Scandinavica, 124, 243-249. http://dx.doi.org/10.1111/j.1600-0447.2011.01705.x

Pase, M. P., Scholey, A. B., Pipingas, A., Kras, M., Nolidin, K., Gibbs, A., Wesnes, K., \& Stough, C. (2013). Cocoapolyphenols enhance positive mood states but not cognitive performance: A randomized, placebo-controlled trial. Journal ofPsychopharmacology, 27, 451-458. http://dx.doi.org/10.1177/0269881112473791

Sanhueza, C., Ryan, L., \& Foxcroft, D. R. (2013). Diet and the risk of unipolar depression in adults: Systematic review of cohort studies. Journal of Human Nutrition and Dietetics, 26, 56-70. http://dx.doi.org/10.1111/j.1365-277X.2012.01283.X

Taylor, M. J., Carney, S. M., Goodwin, G. M., \& Geddes, J. R. (2004). Folate for depressive disorders: Systematic review and meta-analysis of randomized controlled trials. Journal of Psychopharmacology, 18, 251-256.

Young, S. N. (2007). How to increase serotonin in the human brain without drugs. Journal of Psychiatry and Neuroscience, 32, 394-399. 